\title{
A Survey for Mental Health of Children Whose Parents Have Psychiatric Disorders: A Preliminary Study for Mental Health Screening of High Risk Children
}

\author{
Hwo Yeon Seo', Su Mi Park ${ }^{2,3}$, Yeni Kim", Young Hui Yang ${ }^{4}$, \\ Ji Yeuon Lee ${ }^{5}$, Hae Woo Lee ${ }^{6}$, and Hee Yeon Jung ${ }^{2,3,7,8}$ \\ ${ }^{1}$ Department of Psychiatry, Seoul National University Hospital, Seoul, Korea \\ 2Department of Psychiatry, SMG-SNU Boramae Medical Center, Seoul, Korea \\ ${ }^{3}$ Department of Clinical Medical Sciences, Seoul National University College of Medicine, Seoul, Korea \\ ${ }^{4}$ Department of Child and Adolescent Psychiatry, National Center for Mental Health, Seoul, Korea \\ ${ }^{5}$ Dongjak-gu Community Mental Welfare Center, Seoul, Korea \\ ${ }^{6}$ Department of Psychiatry, Seoul Medical Center, Seoul, Korea \\ ${ }^{7}$ Department of Psychiatry and Behavioral Science, Seoul National University College of Medicine, Seoul, Korea \\ ${ }^{8}$ Institute of Human Behavioral Medicine, Seoul National University College of Medicine, Seoul, Korea
}

\section{정신질환을 가진 부모의 자녀들의 정신건강 상태 조사 연구: 고위험군 선별을 위한 예비 연구}

서화연 ${ }^{1}$, 박수미 ${ }^{2,3}$, 김예니 ${ }^{4}$, 양영희 $\left.\right|^{4}$, 이지연 ${ }^{5}$, 이해우 ${ }^{6}$, 정희연 $2,3,7,8$

서울대학교병원 정신건강의학과, ${ }^{1}$ 서울대학교병원운영 서울특별시 보라매병원 정신건강의학과, ${ }^{2}$

서울대학교 의과대학 임상의과학교실, ${ }^{3}$ 국립정신건강센터 소아청소년정신과, ${ }^{4}$ 동작구 정신건강복지센터, ${ }^{5}$

서울의료원 정신건강의학과, ${ }^{6}$ 서울대학교 의과대학 정신건강의학교실, ${ }^{7}$ 서울대학교 의과대학 인간행동의학연구소 ${ }^{8}$

Objectives: This study aimed to evaluate the mental health status of the children of psychiatric patients in order to plan for the resources that may be necessary to help these children achieve their full potential.

Methods: Forty-eight children (age 9-18) whose parents were registered in 5 community mental health centers located in Seoul were recruited. Tests assessing 3 psychological domains were conducted: 1) cognition: Korean version of Learning Disability Evaluation Scale, Comprehensive Attention Test, 2) parent reported emotion and behavior: Korean Child Behavior Checklist, Korean attention-deficit hyperactivity disorder Rating Scale, and 3) self-reported emotion and behavior: Korean Beck's Depression Inventory-II/Children's Depression Inventory-II, Korean Youth Self Report). We defined the children as having a high risk of developing mental health problems if their test scores were over the cut-off levels in 2 or more of the 3 domains assessed.

Results: Twelve (25\%) children were classified as having a high risk of developing mental health issues. 20 (41.6\%) children scored above the cut-off in only one of the domains.

Conclusion: Our results suggest that the children of psychiatric patients might be vulnerable to mental illness and need early prevention or interven-tions for the sake of their mental health.

Key Words: Mental health; High risk; Screening.

Received: April 17, 2017 / Revision: July 13, 2017 / Accepted: August 1, 2017

Address for correspondence: Hee Yeon Jung, Department of Psychiatry, SMG-SNU Boramae Medical Center, 20 Boramae-ro 5-gil, Dongjak-gu, Seoul 07061, Korea

Tel: +82-2-870-2461, Fax: +82-2-870-3866, E-mail: hyjung@snu.ac.kr

\section{서 론}

아동청소년의 정신건강은 개인의 심리적 상태, 학업 성취, 또

This is an Open Access article distributed under the terms of the Creative Commons Attribution Non-Commercial License (http://creativecommons.org/licenses/by-nc/4.0) which permits unrestricted non-commercial use, distribution, and reproduction in any medium, provided the original work is properly cited.
래 관계 및 가족관계 등 광범위한 영역에 영향을 미칠 수 있 다. 초, 중, 고등학생을 대상으로 한 기존의 역학 연구들에 의 하면 약 10 26\%에 달하는 비율의 아동청소년이 정신질환 진 단에 충족할 정도의 문제를 보인다고 보고된 바 있어 이에 대 한 사회적 주목의 필요성이 시사되었다. ${ }^{1)}$ 이들의 정신건강문 제는 학령기에 그칠 뿐만 아니라 장기간 지속되거나 형태가 변 
형된 채 또 다른 문제로 발현되어 성인기가 된 이후에도 직업 기능, 가정생활 유지를 저해하는 등 개인의 일생에 거쳐 부정적 인 영향을 미치며 자살경향 혹은 자살사고를 높이는 극단적 인 결과로 이어지기도 한다. ${ }^{2)}$ 하지만, 이들의 정신과적 문제는 성장 과정 중에 나타나는 일시적인 문제이거나 사춘기 행동 의 일종으로 여겨지며 간과되기 쉽고, 정신질환에 대한 선입견 이나 편견으로 인한 거부감이 높아 정신건강 서비스를 제공하 는 병원 혹은 센터 등의 기관으로 문제가 의뢰되거나 직접 방 문한 비율은 극히 일부에 지나지 않는 실정이다. 따라서 아동 청소년기의 정신건강에 대한 조기 발견 및 개입을 위한 사회적 접근이 필요하다고 볼 수 있다. 또한, 개인의 정신건강 증진을 위해서는 정신질환이 발병하기 이전의 예방이 중요하며, 소아, 청소년 시기에 적절한 예방이 이루어질 때에 보다 효과가 큰 것으로 알려져 있다. ${ }^{3)}$

질병에 대한 효과적인 예방 및 조기 개입을 위해서는 질병에 취약할 수 있는 고위험군을 발견하여 예방적 개입을 실시하는 것이 중요하다. 아동청소년 정신건강 고위험군이란 정신과적 증상이나 징후가 진단기준에 충족할 정도는 아니지만 발견되 는 경우를 의미한다. 고위험군의 선별 및 예방에 있어, 개별적 인 위험도를 기반으로 하지 않고 일반 대중이나 전체 인구를 대 상으로 예방적인 개입을 실시하는 전반적 예방 개입(universal preventive interventions)보다는, 근거-중심적(evidence-based) 인 기반에 근거하여 일반보다 정신질환의 높은 발병위험을 가 지는 인구집단을 대상으로 하는 선택적인 예방 개입(selective preventive intervention)이나, 이미 정신과적 증상이 보고되 고 있는 대상에게 실시하는 지시적 예방 개입(indicated preventive intervention)이 효과적인 것으로 알려져 있다.) 2012 년 보건복지부에서 발표한 정신보건사업안내에 따르면 우리 나라에서는 보건복지부와 교육부의 주관 하에 초, 중, 고등학 교에서 일반 인구집단을 대상으로 학생정서행동특성검사와 같은 선별검사를 실시하고 있다. 또한, 부모나 교사로부터의 보고나 지역사회 유관기관으로부터의 의뢰, 교과부 지정 관 심 대상군, 지역사회 취약계층 발굴, 지역주민 의뢰 등을 통해 아동청소년의 정신건강문제를 조기발견하여 학교 내 상담교사 나 지역사회 정신보건센터, wee center, 청소년 상담센터와 같 은 기관 등에 연계하는 체계를 갖추고 있다. 하지만 현재 국내 의 체계는 주로 학교적응이나 아동청소년 개인의 행동 및 정 서문제에 초점을 맞추고 있으며, 아동청소년 개인뿐만 아니라 생태학적 관점에서 부모, 학교, 지역사회 등을 중요한 축으로 삼는 국외의 선별체계에 비해 한계점을 지닌다. 따라서 유전, 환 경적으로 정신과적 취약성이 높은 대상군을 선택하여 선별적 인 예방개입을 실시하는 체계의 도입이 필요하고 볼 수 있다.

부모가 정신과적 질환을 가진 가정의 경우, 유전, 양육 방식,
가족 역동 및 사회 환경 등의 다양한 요인에 의해 자녀 역시 정신과적 문제를 지니고 있을 확률이 높은 것으로 알려져 왔 다. ${ }^{5)}$ 가령, 부모가 알코올 사용장애가 있을 경우, 입양된 자녀 보다 생물학적인 자녀에게 부모의 알코올 사용장애가 아이의 행동 문제에 미치는 영향이 크다고 보고되었다.) 양육 과정에 서의 부모-자녀 애착 유형과 부모의 행동, 감정 조절 문제 등 도 자녀의 정서 및 성격 발달에 영향을 미치는 주요한 인자로 간주된다.) 산후 우울증이 있었던 산모의 아이를 16 년간 추 적 관찰한 연구에서는, 우울증이 없었던 산모의 아이들에 비 해 기분 장애가 세 배 정도 높게 관찰되었으며, 이 경우 우울증 을 가진 산모의 유아들은 아주 초기부터 불안정 애착이나, 낮 은 탄력 회복성을 보였다. ${ }^{8)}$ 부모와 자녀 사이에서 직접적인 애착 유형뿐만 아니라, 불안정한 가족 체계에 의해 개인의 정 신병리나 행동장애가 나타날 수도 있다." 마지막으로, 부모가 정신질환이 있을 경우 빈곤, 이혼과 같은 취약한 사회환경에 노 출될 위험이 높기 때문에, 아동청소년기 자녀의 정신질환 발병 에 위험 인자가 되기도 한다.10)

위와 같은 다양한 요인과 그의 복합적인 상호작용에 의해 부 모가 정신질환이 있는 경우, 그렇지 않은 경우보다 자녀가 정신 과적 문제를 보일 가능성이 매우 높아질 수 있다. 앞서 언급 하였듯이 현재까지 국내에서 주로 이루어진 소아청소년의 정 신질환 고위험군에 관한 연구는 학교를 중심으로 한 전체 집 단의 유병률 연구에 바탕을 두었으며, 정신질환이 있는 성인 의 자녀에 대한 정신과적 문제에 대한 실태 조사는 제한적으 로 이루어져왔다. ${ }^{11,12)} \mathrm{Cho}$ 등 $^{13)}$ 은 부모 중 한 사람이라도 양극 성 장애를 진단받은 부모의 자녀 100 명을 대상으로 한 연구에 서, $61 \%$ 가 정신과적 진단 기준을 충족함을 보고하였다. Lee 등 14 의 연구에서도 조현병이 있는 부모를 둔 아이들은 정상대조 군의 아이들보다 문제 행동들이 더 많았다는 보고가 있었다. 위와 같은 연구들은 특정 질환을 중심으로 자녀의 정신과적 문제를 조사하였다는 한계를 지니기에, 보다 광범위한 정신과 적 질환을 대상으로 한 연구가 필요하다.

본 연구는 유전적, 환경적 취약성을 지닌 정신질환자의 자녀 가 보이는 정신과적 문제의 실태를 파악하고 정신과적 고위험 군을 발굴하여 효과적인 예방개입을 실시하며, 선별된 대상 자를 주기적으로 추적관리하는 장기 프로젝트의 시행가능성 을 평가하기 위하여 예비연구의 차원으로 실시되었다. 정신건 강 고위험군을 체계적, 조직적, 선택적으로 발굴하기 위해 지 역사회 정신건강증진센터에 등록된 성인회원의 자녀를 연구 대상으로 선정하였다. 이에 본 연구는 다음과 같은 목표를 지 닌다: 1) 지역사회 내의 정신건강증진센터를 이용하는 성인의 자녀를 대상으로 그들의 인지, 정서, 및 행동을 포함하는 정신 과적 문제를 평가하고 정신건강 고위험군을 선별하는 프로토 
콜을 개발, 2) 개발된 프로토콜을 적용하여 정신건강 고위험군 의 현황 및 실태를 파악함.

\section{방 법}

\section{대 상}

본 연구는 정신건강의학과 전문의에게서 정신과적 진단을 받고 약물치료 중인, 서울 소재 5 곳의 정신건강증진센터에 등 록된 성인회원의 아동청소년(연령 만 9 18세) 자녀를 대상으로 실시하였다. 부모의 정신과적 주 진단에 관한 정보는 Table 1에 제시되어 있다. 부모와 자녀 모두가 본 연구에 동의한 경우 평 가하였으며, 최종 48 명의 아동청소년 대상자가 본 연구에 참여 하였다. 본 연구는 2014년 3월부터 12월까지 진행되었으며, 생 명윤리위원회(IRB, 26-2014-42)의 승인을 받은 후 시행되었다.

\section{평가 방법}

\section{평가도구}

본 연구는 아래의 3가지 유형으로 대상자의 정신건강상태 를 평가하였다: 인지기능, 정서 및 행동-부모평정, 정서 및 행 동-자가평정. 각 평가 도구는 해당 연령 규준에 맞게 대상자 에게 적용되었다. 기존의 선별검사 효과성 연구 ${ }^{15)}$ 에 의하면, 소 아청소년에게서 주의력결핍 과잉행동장애(attention-deficit hyperactivity disorder, ADHD)와 우울장애가 가장 유병률이 높 고 이를 선별하는 것이 효과적인 것으로 알려져 있어, 본 연구 에서도 $\mathrm{ADHD}$ 와 우울장애를 평가할 수 있는 검사 도구를 중심 으로 프로토콜을 구성하였다. 또한, 특정 증상뿐만 아니라 전 반적인 증상을 포괄적으로 측정하는 척도를 포함하였다. 이를 위해 문헌리뷰를 통하여 아동청소년 정신건강연구에서 국제 적으로 검증되어왔으며, 구조화된 진단면담 도구와도 교차타 당도가 높은 검사 도구 목록을 수집하였다. ${ }^{16,17)}$

\section{인지기능}

(1) 한국판 학습장애 평가척도(Korean version for Learning Disability Evaluation Scale, K-LDES)

Shin 등이이 아동의 학습능력을 측정하기 위해 고안한 척도 로, 부모나 교사가 7개의 하위영역(주의력, 사고력, 말하기, 읽 기, 쓰기, 철자법, 수학적 계산)에서 보이는 아동의 학습 능력 이나 문제에 관해 평정하도록 되어 있다. 본 연구에서는 만 9 11세에 해당하는 대상자에게 적용되었으며, 임상적 절단점 은 70점 이하이다.

(2) 종합주의력 검사(Comprehensive Attention Test, CAT)
아동과 청소년의 주의력과 전두엽기능을 종합적으로 평가하 기 위해 개발한 컴퓨터 기반 전산화 검사이다. ${ }^{19)}$ 종합주의력은 단순주의력, 선택주의력, 지속주의력, 분할주의력, 작업기억력 등 5 가지 종류의 검사로 구성되어 있으며, 각 검사당 누락오 류, 오경보오류, 반응시간, 반응시간 표준편차에 대한 정상, 경 계, 저하 수준과 주의력지수(Attention Quotient, AQ)가 제시 된다. Comprehensive Attention Test(CAT) 매뉴얼에 따르면 이 중 누락오류, 오경보오류, 반응시간 편차의 요인 부하량이 높은 것으로 밝혀져, 본 검사에서는 5 가지 검사의 누락오류, 오경보오류, 반응시간 편차의 $\mathrm{AQ}$ 의 평균을 구하여 종합주의 력 $\mathrm{AQ}$ 를 산출하였다. 작업기억검사는 순방향(정반응 수, 공 간주의 폭)과 역방향(정반응 수, 공간주의 폭)으로 구성되어 있어 총 4 가지의 $\mathrm{AQ}$ 가 산출된다. 본 검사에서는 4 가지 척도 의 $\mathrm{AQ}$ 의 평균을 구하여 작업기억 $\mathrm{AQ}$ 를 산출하였다. 본 연구 에서는 만 9 15세에 해당하는 대상자에게 적용되었으며, 종 합주의력 $\mathrm{AQ}$ 혹은 작업기억 $\mathrm{AQ}$ 가 70점 이하에 해당할 경우 임상적 절단점 기준을 충족하는 것으로 간주되었다.

\section{정서 및 행동-부모평정}

(1) 한국판 주의력결핍 과잉행동장애 평정척도(Korean-ADHD Rating Scale, K-ARS)

Dupaul ${ }^{20)}$ 이 개발하여 국내에서 표준화되었다. ${ }^{21)}$ 정신장애의 진단 및 통계 편람 제4판(Diagnostic and Statistical Manual of Mental Disorders-forth edition, 1994)의 ADHD 진단 기준 을 18 개의 문항으로 재구성한 척도이며, 과잉행동과 산만함을 측정한다. 국내 표준화는 초등학교 학생들을 대상으로 하였 으나, 영어 버전의 경우 18 세까지 사용 가능하여 본 연구에서는 전 연령에게 적용하였다. 임상적 절단점은 19 점 이하이다.

(2) 한국판 아동행동평가척도(Korean Child Behavior

Checklist, K-CBCL)

Achenbach ${ }^{22)}$ 가 개발한 Child Behavior Checklist(CBCL) 는 아동 및 청소년(만 4 18세)의 사회 적응 및 정서행동 문제 전반을 평가하기 위해 전 세계적으로 유용하게 사용되고 있는 척도로, 한국판 $\mathrm{CBCL}(\mathrm{K}-\mathrm{CBCL})$ 은 부모 혹은 아동청소년을 잘 알고 있는 양육자가 평정하도록 되어 있다. ${ }^{23}$ 9개의 소척도 (불안/우울, 위축/우울, 신체증상, 사회적 미성숙, 사고문제, 주 의집중문제, 규칙위반, 공격행동, 기타문제)로 이루어져 있으며, 이는 내재화 척도와 외현화 척도로 재구성되고, 이를 종합한 문제행동총점이 매겨진다. 또한, 아동청소년의 사회적응수준 을 측정하기 위해 사회성 및 학업수행척도로 구성된 적응척 도총점이 매겨진다. 본 연구에서는 등록된 전 연령의 대상(만 9 18세)에게 적용되었으며, 문제행동총점의 T점수가 64 이상 
혹은 적응척도총점이 T점수 36 이하일 경우 임상적 절단점 기 준을 충족하는 것으로 간주되었다.

정서 및 행동-자가평정

(1) 우울척도

(ㄱ) 한국판 벡 우울척도 2판(Korean Beck's Depression Inventory-II, K-BDI-II) ${ }^{24)}$

Beck 등 ${ }^{25}$ 이 개발하고 개정한 자기보고식 척도로 우울증상 의 유무와 증상의 심각성 정도를 함께 평가할 수 있다. 0 점부 터 3점까지의 리커트 척도로, 총 21문항으로 구성되어 있다. 본 연구에서는 만 13 18세의 대상자에게 적용되었으며, 중등 도 우울수준인 16점 이상에 해당할 경우 임상적 절단점 기준 을 충족하는 것으로 간주되었다.

(ㄴ) 아동기 우울척도 2판(Children's Depression Inventory-

\section{II, CDI-II)}

Kovasc $^{26)}$ 가 개발한 자기보고식 아동용 우울척도로 Beck's Depression Inventory-II(BDI-II)의 변형본이다. 0점부터 2점 까지의 28 개 문항으로 구성되어 있으며, 정서문제와 기능문제 를 평가한다. 본 연구에서는 만 9 12세의 아동에게 실시되었 으며 임상적 절단점은 22점 이상이다.

(2) 한국판 청소년 행동평가척도 자기보고용(Korean-Youth

Self Report, K-YSR) ${ }^{27)}$

Achenbach와 Edelbrock ${ }^{28)}$ 이 개발한 문제 행동과 사회적응 전반을 측정하기 위한 청소년용 자기보고식 평가도구이다. 본 연구에서는 만 16 18세의 대상자에게 적용되었으며, 척도의 구성 및 임상적 절단점은 $\mathrm{K}-\mathrm{CBCL}$ 과 동일하다.

\section{자료수집}

정신건강증진센터의 회원인 부모와 자녀 모두가 연구에 대 한 설명을 듣고 참여에 동의한 경우, 성인회원의 자녀가 대상 자로 등록되었다. 보호자 평정의 경우, 주 양육자를 기본으로 하되, 심한 정신질환으로 평가가 불가능할 경우, 대상자와 가 장 가까운 양육자로 대신하였다. 본 연구에 동의한 최종 대상 자는 모두 어머니가 정신건강증진센터 회원이자 주 양육자였 다. 부모와 자녀의 인구통계학적 정보를 수입한 이후, 대상자의 연령에 해당하는 규준을 적용하여 인지, 정서 및 행동-부모평 정용, 정서 및 행동-자가평정용 평가를 실시하였다.

\section{고위험군의 정의}

한 선행연구에 의하면, 정신건강 위험군을 선별하기 위해서 는 단일-정보제공자보다 다중-정보제공자로부터 정보를 종합
적으로 수집하여 고려할 때에 선별 민감도가 높아질 수 있다.29) 본 연구는 선별기준의 객관성을 확보하고 단일 검사를 통해 고위험군으로 과잉선별되는 오류를 낮추기 위해 소아청소년 전공 공동연구자들의 토의를 거쳐 다음과 같이 종합적인 기준 으로 '고위험군(high risk)'을 정의하였다(Table 1); 1) 인지평 가, 2) 정서 및 행동-자가평정, 3) 정서 및 행동-부모평정의 3가 지 영역 중 2개 이상의 영역에서 임상범위 절단점(cut off score) 을 충족한 자. 상기 3 영역 중 1 개의 영역에서 임상범위 절단점 을 충족한 자 역시 주의가 요망되기에 '주의군(moderate risk)' 으로 간주하였다. 모두에 해당하지 않는 경우에는 '정상군 (normal)'으로 정의하였다.

검사 후에는 모든 대상자의 부모에게 정신건강증진센터의 사례담당자를 통하여 고위험군, 주위군, 정상군에 대한 임상 적 판정 결과와 설명을 제공, 전달하고 고위험군에 해당할 경우 정신건강서비스 기관에 방문할 것을 권고하였다.

\section{자료분석}

고위험군과 주의군에 해당하는 인원의 비율과 인구통계학 적 특성을 파악하기 위해 기술통계와 빈도분석을 시행하였다. 고위험군과 주의군, 정상군의 인구학적 비교 방법으로 분산 분 석과 교차분석(Fisher의 정확검정)을 시행하였다. 추가로 검사 별 평균, 표준 편차, 범위 등의 기술통계량을 구하였다. 수집된 자료를 분석하기 위해 IBM Statistical Package for the Social Science statistics version 19.0(IBM Corp., Armonk, NY, USA) 을 이용하였다.

\section{결 과}

\section{전체 대상자의 인구학적 변인 특성}

전체 대상의 인구 통계학적 변인 특성은 Table 1과 같다. 총 48 명의 초, 중, 고등학생이 본 연구에 참여하였으며, 평균 연령 은 13.23세(표준편차 2.47)였고, 남녀의 성비는 50\% 대 50\%로 동일하게 구성되었다. 부모의 정신질환으로는 우울증 (31명, 64.58\%)이 가장 많았고, 정신분열(11명, 22.91\%)과 조울증(3명, 6.25\%)이 다음 순을 이루었다. 사회경제적 수준(socio-economic status)은 하(29명, 60.41\%)와 중하(10명, 20.38\%)에 속 하는 비율이 높았던 바, 대상자 가정의 사회 경제적 상황이 취 약함을 알 수 있다.

\section{전체 대상자의 검사별 기술통계}

고위험군을 선별하기에 앞서, 각 검사별로 절단점 기준에 충족되어 임상범위에 해당하는 대상자의 빈도를 살펴보았다 (Table 2). 그 결과, CAT의 종합주의력에서 약 $10 \%$, 작업기억 
력에서 약 $23 \%$ 의 대상자가 임상범위에 해당하였으며, K-ARS 에서는 약 $23 \%$ 의 대상자가 임상범위에 해당하여 주의집중력 의 문제가 시사되었다. K-ARS 부모평정 행동체크리스트에서 는 문제행동척도에서 $40.43 \%$, 적응척도에서 $25.00 \%$ 의 대상자 가 임상범위에 속하였다. K-BDI-II에서는 약 $17.39 \%$, Children's

Table 1. Demographic characteristics of participants

\begin{tabular}{lc}
\hline & Participants $(\mathrm{n}=48)$ \\
\hline Age, mean (standard deviation) & $13.23(2.47)$ \\
Sex, $\mathrm{n}(\%)$ & $24(50.00)$ \\
Male & $24(50.00)$ \\
Female & \\
Education, $\mathrm{n}(\%)$ & $16(33.33)$ \\
Elementary & $24(50.00)$ \\
Middle & $7(14.59)$ \\
High & $1(2.08)$ \\
Etc. & \\
Parents' diagnosis, $\mathrm{n}(\%)$ & $31(64.58)$ \\
Depression & $11(22.91)$ \\
Schizophrenia & $3(6.25)$ \\
Bipolar disorder & $3(6.25)$ \\
Etc. & \\
Birth record, $\mathrm{n}(\%)$ & $5(10.42)$ \\
Pre term & $40(83.33)$ \\
Full term & $1(2.08)$ \\
Post term & $1(2.08)$ \\
Unknown & $1(2.08)$ \\
No response & \\
Socio-economic status, $\mathrm{n}(\%)$ & $0(0.00)$ \\
High & $4(8.33)$ \\
High middle & $4(8.33)$ \\
Middle & $10(20.38)$ \\
Low middle & $1(2.08)$ \\
Low & \\
No response & \\
\hline
\end{tabular}

Depression Inventory-II(CDI-II)에서는 $28.00 \%$ 로, 대상자의 높은 비율이 우울문제를 겪고 있는 것으로 나타났다. K-YSR 자기보고 평정 척도 중 문제행동 척도에서는 $22.22 \%$, 적응척 도에서는 $33.33 \%$ 의 아동청소년이 임상범위에 해당하였다.

아동청소년의 문제행동 목록을 상세히 살펴보기 위해, $\mathrm{CBCL}$ 부모평정 행동체크리스트의 하위항목 및 소척도 기술통계 분 석을 추가로 실시하였다. 그 결과, 문제행동척도 중 내현화 하 위척도의 평균값은 59.67(표준편차 13.54)이었으며, $41.67 \%$ 에 달하는 대상자가 임상범위에 속하는 것으로 나타났다. 외재화 하위척도의 평균값은 59.25(표준편차 12.97)였으며, $31.25 \%$ 의 대상자가 임상범위에 속하였다. 또한 적응척도 중 사회성 하위 척도의 평균값은 45.44(표준편차 10.21)였으며, $4 \%$ 의 아동청소 년이 임상범위에 속하였다. 학업 하위척도의 평균값은 45.44 (표준편차 11.02)로, $4 \%$ 의 아동이 학업성취에 있어 임상적인 수 준의 어려움을 겪는 것으로 나타났다. 소척도별로 임상범위에 해당한 대상자의 비율을 살펴보면, 위축/우울이 $18.75 \%$, 주의 집중문제가 $16.67 \%$ 로 가장 많은 아동청소년이 임상적 수준의 문제를 겪고 있는 소척도로 나타났다. 또한 불안/우울과 사회 적 미성숙 및 규칙위반 소척도 모두에서 $14.58 \%$ 의 대상자가 임상범위에 속하는 것으로 나타났다. 그 밖에 신체증상에서 $6.25 \%$ 의 아동청소년이 임상범위에 속하는 문제를 보이는 것 으로 보고되었으며, 임상적 수준의 사고문제를 보이는 아동 청소년은 $4.17 \%$ 로 보고되었다.

\section{정신건강 고위험군 집단에 따른 기술통계}

본 연구에서의 판정 기준에 따라 고위험군으로 분류된 대상 자는 48 명 중 12 명으로 $25 \%$ 에 달하였다. 또한, 주의군과 정상 군에는 각각 20명(41.67\%)과 16명(33.33\%)이 해당하였다(Fig. 1). Table 3은 고위험, 주의 및 정상군의 집단별 인구통계학적 특 성을 보여준다. 남아의 $29.17 \%$ 가 고위험군, $45.83 \%$ 가 주의군

Table 2. Descriptive statistics and number of participants in the clinical range for each test

\begin{tabular}{|c|c|c|c|c|c|c|}
\hline & $\mathrm{n}$ & Min & Max & Mean & Standard deviation & Clinical range, $\mathrm{n}(\%)$ \\
\hline K-LDES & 8 & 89.00 & 113.00 & 101.88 & 9.34 & $0(0.00)$ \\
\hline CAT comprehensive attention & 39 & 43.67 & 118.53 & 87.72 & 14.55 & $4(10.26)$ \\
\hline CAT working memory & 39 & 27.50 & 130.50 & 84.47 & 21.99 & $9(23.08)$ \\
\hline K-ARS & 47 & 0.00 & 50.00 & 12.68 & 11.16 & $8(23.40)$ \\
\hline K-CBCL behavioral problem & 48 & 39.00 & 91.00 & 60.23 & 13.86 & $19(40.43)$ \\
\hline K-CBCL social competence & 48 & 20.00 & 75.00 & 44.63 & 11.80 & $12(25.00)$ \\
\hline K-BDI-II & 23 & 23.00 & 35.00 & 11.91 & 8.39 & $4(17.39)$ \\
\hline CDI-II & 25 & 0.00 & 30.00 & 15.76 & 8.16 & $11(28.00)$ \\
\hline K-YSR behavioral problem & 9 & 51.00 & 78.00 & 59.44 & 8.35 & $2(22.22)$ \\
\hline K-YSR social competence & 9 & 19.00 & 63.00 & 41.89 & 13.37 & $3(33.33)$ \\
\hline
\end{tabular}

K-ARS: Korean-ADHD Rating Scale, K-BDI-II: Korean Beck's Depression Inventory-II, CAT: Comprehensive Attention Test, K-CBCL: Korean Child Behavior Checklist, CDI-II: Children's Depression Inventory-II, K-LDES: Korean version for Learning Disability Evaluation Scale, K-YSR: Korean-Youth Self Report 


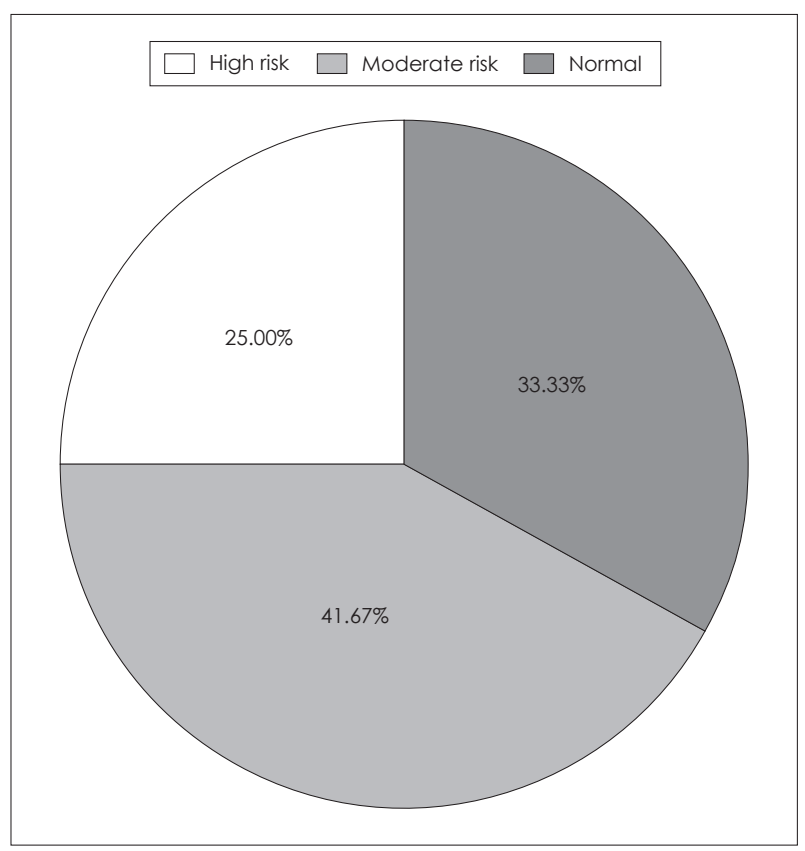

Fig. 1. Proportion of high risk chidren for mental health.
에 속하였으며 여아의 경우 $20.83 \%$ 가 고위험군, $37.50 \%$ 가 주 의군에 해당하였다. 부모 진단에 따른 고위험군 분포를 살펴 보면, 부모의 진단이 우울증인 경우 $29.03 \%$ 가 고위험군, $38.70 \%$ 가 주의군에 속하였다. 부모의 진단이 정신분열인 경우에는 $18.18 \%$ 가 고위험군, $45.46 \%$ 가 주의군에 해당하였다. 부모의 진단이 조울증인 자녀 3명 중 1명(33.33\%)은 고위험군, 2명 (66.67\%)은 주의군으로 선별되었으며, 정상군에 속하는 자녀 는 부재하였다. 집단별 인구학적 특성에 따른 통계학적 차이 를 분석하기 위해 분산분석과 교차분석을 실시한 결과 연령, 성별, 교육, 부모 진단, 출산력 및 사회 경제력에 따른 집단 간 차이는 모두 유의하지 않았다( $\mathrm{p}>0.05)$.

\section{고 찰}

본 연구는 정신건강 고위험군을 발굴하고 장기추적관리 시 스템을 구축하기 위한 예비 단계의 일환으로 실시되었다. 국 내의 기존 정신건강 고위험군 선별연구는 초, 중, 고등학교 학

Table 3. Demographic characteristics for each group

\begin{tabular}{|c|c|c|c|}
\hline & High risk group & Moderate risk group & Normal group \\
\hline No. (\%) & $12(25.00)$ & $20(41.67)$ & $16(33.33)$ \\
\hline Age, mean (standard deviation) & $13.25(2.73)$ & $13.30(2.64)$ & $13.19(2.17)$ \\
\hline \multicolumn{4}{|l|}{ Sex, n (\%) } \\
\hline Male & $7(29.17)$ & $11(45.83)$ & $6(25.00)$ \\
\hline Female & $5(20.83)$ & $9(37.50)$ & $10(41.67)$ \\
\hline \multicolumn{4}{|l|}{ Education, n (\%) } \\
\hline Elementary & $4(25.00)$ & $7(43.75)$ & $5(31.25)$ \\
\hline Middle & $7(29.17)$ & $9(37.50)$ & $8(33.33)$ \\
\hline High & $0(0.00)$ & $4(57.14)$ & $3(42.86)$ \\
\hline Etc. & $1(100.00)$ & $0(0.00)$ & $0(0.00)$ \\
\hline \multicolumn{4}{|l|}{ Parents' diagnosis, n (\%) } \\
\hline Depression & $9(29.03)$ & $12(38.70)$ & $10(32.26)$ \\
\hline Schizophrenia & $2(18.18)$ & $5(45.46)$ & $4(36.37)$ \\
\hline Bipolar disorder & $1(33.33)$ & $2(66.67)$ & $0(0.00)$ \\
\hline Ełc. & $0(0.00)$ & $1(33.33)$ & $2(66.67)$ \\
\hline \multicolumn{4}{|l|}{ Birth Record, n (\%) } \\
\hline Pre term & $1(20.00)$ & $2(40.00)$ & $2(40.00)$ \\
\hline Full term & $10(25.00)$ & $16(40.00)$ & $14(35.00)$ \\
\hline Post term & $1(100.00)$ & $0(0.00)$ & $0(0.00)$ \\
\hline Unknown & $1(100.00)$ & $0(0.00)$ & $0(0.00)$ \\
\hline No response & $0(0.00)$ & $1(100.00)$ & $0(0.00)$ \\
\hline \multicolumn{4}{|l|}{ Socio-economic status, n (\%) } \\
\hline High & $0(0.00)$ & $0(0.00)$ & $0(0.00)$ \\
\hline High middle & $1(25.00)$ & $1(25.00)$ & $2(50.00)$ \\
\hline Middle & $1(25.00)$ & $1(25.00)$ & $2(50.00)$ \\
\hline Low middle & $2(20.00)$ & $6(60.00)$ & $2(20.00)$ \\
\hline Low & $8(27.59)$ & $11(37.93)$ & $10(34.48)$ \\
\hline No response & $0(0.00)$ & $1(100.00)$ & $0(0.00)$ \\
\hline
\end{tabular}


생들을 대상으로 광범위하게 진행되었거나, 우울, 주의력 결 핍, 자살심각도와 같은 특정 정신과적 문제에 초점을 두고 진 행되었다. 최근, 국내 정신보건체계 내에서 아동청소년의 기 능을 포괄적으로 평가하기 위한 선별척도 개발 예비연구가 진 행되었으나, 초등학생 대상으로만 제작되어 다양한 연령의 아 동청소년에게 확대적용하기에는 어렵다고 볼 수 있다. ${ }^{30)}$ 이와 달리 본 연구는 정신질환이 있어 정신건강증진센터에 등록된 성인의 초, 중, 고등학생 아동청소년 자녀로 선별 대상자를 특 정 지었으며, 정서 및 행동 문제에 대한 부모평정과 자녀평정 및 신경인지평가를 실시하여 다각도로 정신과적 문제에 접근 하였다는 차별성을 지닌다. 그 결과 약 3 분의 2 에 해당하는 아 동청소년이 1 개 이상의 검사에서 정신건강 이상 징후를 보이 는 것으로 시사되었다. 특히, 4 분의 1에 달하는 아동청소년은 정신건강 고위험군으로 분류되어 추적관리가 필요한 것으로 나타났다. 하지만 선별검사 실시 당시 실제로 의료센터의 정신 건강의학과나 정신건강관련 기관에서 치료적 개입을 받고 있 는 아동청소년은 12 명의 고위험군 대상자 중 단 2 명에 불과하 였다. 정신건강의학적 개입이 필요하지만 여전히 도움을 받지 못하고 있는 아동청소년을 위해, 지역사회적인 수준에서 정신 건강에 대해 주기적인 선별검사와 치료적 개입을 실시하고 이 를 장기적으로 추적 관찰하는 시스템이 구축되어야할 필요성 이 재입증되었다고 볼 수 있다.

본 연구에서는 부모의 정신질환이 없는 대조군 혹은 일반 집 단과의 비교를 직접 실시하지는 못하였다. 하지만 일반 인구집 단을 대상으로 한 기존의 연구 결과와 간접 비교해 보았을 때 에 정신질환이 있는 성인의 자녀의 정신건강이 더욱 취약함을 알 수 있다. 보건복지부와 교육부의 주관 하에 매해 실시되는 학생정서행동특성 검사 결과에 의하면 약 $10 \%$ 내외가 정신건 강 고위험군으로 보고되고 있으며, 2013년 실시된 55개의 초, 중, 고등학교 대상 전수조사에서는 1234 명의 아동청소년이 정 신건강 사례관리가 필요한 집단으로 분류되었다. ${ }^{31)}$ 또한 본 연구와 유사한 검사도구를 사용한 2005년 서울시 역학사업 연구 ${ }^{12}$ 결과를 살펴봄으로써 전체 초, 중, 고등학생 표본과 본 연구 대상자의 정신건강 상태 비교를 시도하였다. 자기보고식 우울척도와 $\mathrm{K}-\mathrm{CBCL}$ 이 개정되어, 본 연구와 2005년 역학연구 결과를 직접적으로 비교하는 것에는 한계가 존재하지만, 정신 건강정도의 대략적인 윤곽에 대한 간접 비교가 가능하다고 볼 수 있다. 그 결과, 전체집단 대상에서 우울증 임상척도(BDI, $\mathrm{CDI}$ 를 통해 중등도(moderate) 이상의 우울문제를 보이는 아 동청소년은 총 $3.11 \%$ 로 보고된 반면, 본 연구에서 우울증 임상 척도(K-BDI-II, CDI-II)의 중등도(moderate) 이상에 해당하는 아동청소년은 총 $31.25 \%$ 에 달하는 것으로 나타났다. $\mathrm{K}-\mathrm{CBCL}$ 에서도 문제행동 및 적응척도에서 본 연구 $(40.43 \%, 35 \%)$ 에서
전체집단 $(5.56 \%, 10.08 \%)$ 보다 높은 비율이 $\mathrm{K}-\mathrm{CBCL}$ 해당 척 도의 절단점을 충족하는 수준의 어려움을 겪고 있는 것으로 보고되었다.

일반 인구집단보다 정신질환자 자녀의 정신과적 취약성이 높은 결과는 선행 연구결과와도 일치하는 양상이다. Rasic 등 32 은 33개 연구의 메타분석을 통해 부모가 조현병, 조울증 등의 심각한 정신질환이 있는 경우 그 자녀는 성인기까지 $32 \%$ 의 확 률로 심각한 정신질환이 이환되는데, 이는 일반 인구집단의 두 배에 해당하는 위험도임을 밝혔다. 또한 Dean 등 33 은 865078 명이 등록된 덴마크 코호트를 분석하여 부모의 정신질환은 아이의 정신과적 문제의 위험도를 증가시키는 것을 관찰하였 고, 특히 두 부모가 모두 질환을 가지고 있을 경우 가장 강한 상 관관계가 있음을 보였다. 하지만, 위와 같은 연구 결과가 정신과 적 질환이 있는 환자 및 그들의 자녀에 대한 낙인효과(stigma) 를 발생시키지 않도록 주의가 필요하다.

부모의 정신질환 외에도 다양한 환경요인이 아동청소년의 정신건강에 영향을 미칠 수 있다. $\mathrm{K}-\mathrm{CBCL}$ 을 이용하여 미국 내 국가적인 정신건강 선별검사를 진행한 연구에 의하면, 아동 학대를 경험하고 아동복지 센터와 연계된 2 14세의 아동청소 년의 $47.9 \%$ 로 약 절반가량에 이르는 대상자가 문제행동척도 에서 임상적 수준의 문제를 나타내는 것으로 보고되었다. ${ }^{17)}$ 그 밖에 사회경제적 취약성 요인, 탈북 혹은 난민 가정, 부모의 이 혼과 사별 등으로 인한 가족구조 변화 등 다양한 가정 요인이 아동청소년의 정신건강에 위험요인으로 작용할 가능성이 있 다. 따라서 전수를 대상으로 하는 예방적 개입도 중요하지만, 정신건강에 취약성을 지니는 대상들에게 선택적 예방개입과 선 별, 관리를 적극적으로 실시할 수 있는 국가적 차원의 체계와 정책이 수립되어야 할 것이다.

본 연구는 다음과 같은 한계점을 지니고 있다. 지역사회 정신 건강증진센터 등록 회원의 구성이 중증 정신질환자(예: 만성 정신병) 위주로, 독신이거나 자녀가 없는 경우가 많았다. 이에 회원의 자녀를 모집해야 하는 본 연구에서 연구 기준에 해당 하는 대상자를 발굴하기에 어려움이 있었다. 또한, 자녀가 있는 경우에도 부모의 인지장해 또는 동기 부족으로 자녀평정이 어 려운 경우가 많았고, 연구참여 동의율도 저조한 편이었다. 본 연구에서 대상자에 대한 평가는 주 양육자가 하되 심한 정신질 환으로 평가능력에 문제가 있을 경우에는 대상자와 가장 가까 운 관계에 있는 양육자가 대신할 것을 제안하였지만, 가까운 양 육자도 부재하는 경우가 많았다. 본 연구의 적은 표본수로 인 해 통계적 검정력을 확보하는 데에는 한계가 따랐다. 추후의 연구에서는 보다 많은 대상자 확보를 위하여 대상자의 교사 평정 등을 추가하는 방안을 고려해 볼 수 있겠다. 또한, 부모 의 정신의학적 상태에 따라 융통성 있게 프로토콜을 적용하 
고, 조손 가정, 결손 가정으로 친인척이 양육하나 주 양육자 가 정신건강증진센터의 회원인 경우 등으로 연구의 대상을 확 대하여 연구 등록률과 추적률을 높일 것을 제안하는 바이다. 향후 유전적 취약성과 환경적 위험을 공유하고 있는 연구대상 자를 더 많이 모집하기 위해서는 병원의 정신건강의학과, 심리 상담센터 등과 같이 정신건강관련 기관에 방문하고 있는 사람 들의 자녀군까지로 대상자를 확대하는 방안도 도움이 될 수 있 을 것이다.

둘째, 본 연구는 정신건강 고위험군을 선별하는 프로토콜을 개발하는 것에 의의를 두었기에 선별과정 실시의 효용성을 높 이기 위해 본 프로토콜에는 임상가가 직접 실시하는 구조화된 진단면접이 포함되지 않았다. 이에 본 연구에서 실시된 프로 토콜은 정신건강 고위험군으로 선별된 대상자의 진단적 정보 까지는 제공하지 못한다는 한계를 지닌다. 추후에는 보다 큰 표본수를 확보하여 질문지형 검사, 인지기능 검사 및 구조화 된 진단면접 간의 관계성을 분석하고 통합적인 선별 및 진단 시스템을 구축하는 연구가 진행되어야 함을 제안한다. 임상가 가 직접 대면하지 않는 프로토콜의 단점을 보완하기 위해 본 연구에서는 부모 보고 및 자녀 보고의 질문지형 검사와 전산 화된 주의력 평가를 실시하여 정서, 인지, 행동에 이르는 다차 원적 문제를 평가하고자 하였다. 또한, 단일 검사 결과만으로 정신질환 고위험군으로 과잉분류되는 오류를 줄이고 타당도 를 확보하기 위하여 1) 인지평가, 2) 정서 및 행동-자가평정, 3) 정서 및 행동-부모평정의 3 가지 영역 중 2 개 이상의 영역에서 임상적 문제가 시사되는 경우에 고위험군으로 정의하였다. 하지 만, 인지평가에 포함된 K-LDES 학습평가도 부모의 평정을 통 해 이루어지기 때문에 인지기능에 대한 간접적인 정보를 제공 한다는 한계를 지닌다. CAT 주의력 검사는 인지기능에 대한 직접적인 정보를 제공하지만, 규준 문제로 만 16 세 이상의 대 상자에게는 실시되지 않았다. 따라서, 만 16세 이상 혹은 고등 학생의 경우 정서 및 행동에 관한 자가평정과 부모평정 모두 에서 임상문제가 보고되어야지만 고위험군으로 분류될 수 있 었다. 대상자 본인이나 부모가 정서 및 행동문제에 관한 통찰 (insight)이 부족한 경우에는 축소 판단되었을 가능성이 있다.

부모의 정신의학적 진단의 경우에는 기존에 병원에서 진단 을 받고 정신건강증진센터에 등록된 진단명을 사용하였기에, 본 연구진이 직접 부모의 정신건강상태에 대한 자세한 임상평 가를 실시하지 않았다는 한계를 지닌다. 따라서, 연구 시점에서 의 진단적 정확성이 부족할 가능성을 배제할 수 없으며, 정신 과적 질병의 기간, 심각도 등 보다 구체적인 임상적 정보가 분 석에 고려되지 않았다. 마지막으로, 본 연구의 형태가 실태조 사이며 기타 가족 구조, 가정 내 폭력 여부 등 기타 변인에 대 한 면밀한 탐색이 이루어지지 않았기 때문에, 부모의 정신질
환이 자녀의 정신건강에 직접적으로 영향을 미쳤는지에 관한 인과관계를 밝히는 데에 제한점이 있다.

본 연구는 지역사회 내에서 아동청소년 정신건강 고위험군 에게 효과적으로 접근하고 평가하여, 적극적인 개입과 지속 적 추후관리를 가능케 하며, 예방적으로 접근하게 하는 초석 을 마련하는 점에서 의의를 지닌다. 국외에서 실시된 연구들 에 의하면 정신질환이 있는 부모의 자녀에 있어서, 생물학적 이고, 심리적이고, 사회적인 위험요소 및 예방 요소를 알아내 어, 정신건강을 향상시키거나 질병 초기에 개입하는 것이 중요 하다. 부부 치료, 부모의 정신 질환의 치료, 양육 훈련 등의 다 양한 개입이 아동의 정신질환에 예방적 효과가 있다고 밝혀 겼다. 최근의 메타분석에서는 예방적 개입을 통해 부모와 같은 정신질환을 발현할 위험성이 $40 \%$ 까지 감소될 수 있다고 보고 되었다. ${ }^{34)}$ 이와 같은 맥락에서 본 연구의 아동청소년 대상 정 신건강 고위험군에 관한 결과는 개인과 가족의 심리적 안녕감 뿐만 아니라 사회 경제적 비용의 감소 효과 불러올 수 있는 예 방 및 치료적 개입의 근거를 마련할 수 있을 것이라 기대한다.

\section{결 론}

본 연구는 정신질환을 가진 환자 자녀의 정신건강 현황을 파 악하고 정신건강 선별검사 체계를 구축하고자 하였다. 그 결 과, 지역사회 정신건강증진센터에 등록된 성인회원의 자녀들 중 상당수의 아동청소년이 정신과적 취약성을 가지고 있으며, 본 연구가 정한 고위험군 기준을 충족하는 아동청소년은 약 $25 \%$ 에 달하는 것으로 나타났다. 이는 정신질환이 있는 사람 들의 자녀의 정신건강을 위한 지역 사회적 수준의 예방과 관 리를 위한 선별 및 치료적 개입 체계가 구축되어야 할 필요성 을 시사한다.

중심 단어: 정신건강; 고위험군; 선별검사.

\section{Acknowledgments}

This study was supported by a research fund from Seoul National Hospital, Ministry of Health \& Welfare, Republic of Korea.

\section{Conflicts of Interest}

The authors have no financial conflicts of interest

\section{REFERENCES}

1) Ahn DH. Mental disorders in adolescents. J Korean Med Assoc 2009; 52:745-757.

2) Shin MS, Park KB, Oh GJ, Kim JS. A study of suicidal ideation among high school students: the structural relation among depression, hopelessness, and suicidal ideation. Korean J Clin Psychol 1990;9:1-19.

3) Hawkins JD, Kosterman R, Catalano RF, Hill KG, Abbott RD. Effects of social development intervention in childhood 15 years later. Arch Pediatr Adolesc Med 2008;162:1133-1141. 
4) Weisz JR, Sandler IN, Durlak JA, Anton BS. Promoting and protecting youth mental health through evidence-based prevention and treatment. Am Psychol 2005;60:628-648.

5) Kim YH, Chung KH, Oh HS, Shin YJ, Yang YJ, Chung EH, et al. A study of mental health state and family function of parents with a mentally disabled person. J Korean Acad Psychiatr Ment Health Nurs 2009;18:332-340.

6) King SM, Keyes M, Malone SM, Elkins I, Legrand LN, Iacono WG, et al. Parental alcohol dependence and the transmission of adolescent behavioral disinhibition: a study of adoptive and nonadoptive families. Addiction 2009;104:578-586.

7) Jung ES, Cho HI. The effects of parental care and overprotection on subjective well-being and depression: the roles of hardiness and perfectionism as mediators. Korean J Couns Psychother 2009;21: 209-227.

8) Oyserman D, Mowbray CT, Meares PA, Firminger KB. Parenting among mothers with a serious mental illness. Am J Orthopsychiatry 2000;70:296-315.

9) Gurman AS, Kniskern DP. Handbook of family therapy. New York: Routledge; 1981.

10) Mattejat F, Remschmidt $\mathbf{H}$. The children of mentally ill parents. Dtsch Arztebl Int 2008;105:413-418.

11) Lee TH, Lee YJ. Prevalence and related risk factors of suicidal ideation in urban adolescents. Sleep Med Psychophysiol 2014;21:61-68.

12) Cho SC, Go BJ, Kim B, Kim BN, Kim JW, Shin MS, et al. Epidemiological Report in 2005: prevalence of psychiatric disorders of child and adolescent in Seoul. Seoul Metropolitan, Seoul School Health Promotion Center, Department of Child and Adolescent Psychiatry, Seoul National University Hospital, Seoul Children \& Adolescent Metropolitan Mental Health Center; 2006.

13) Cho YS, Lee HY, Kwon YJ, Jeong HY, Shin JY, Shim SH. Mental disorders in offspring of parents with bipolar disorder. J Korean Neuropsychiatr Assoc 2014;53:310-319.

14) Lee SH, Kang KM, Kwack YS. Rearing pattern of schizophrenic mothers and their children's behaviour problems. J Korean Acad Child Adolesc Psychiatry 1998;9:180-189.

15) Kim HJ, Cho SC, Kim JW, Kang JW, Shin MS, Kim HW, et al. The effectiveness of mental health problems screening and treatment linkage in children \& adolescents: community based study focused on ADHD and depression. J Korean Acad Child Adolesc Psychiatry 2009;20:129-139.

16) Fazel M, Reed RV, Panter-Brick C, Stein A. Mental health of displaced and refugee children resettled in high-income countries: risk and protective factors. Lancet 2012;379:266-282.

17) Burns BJ, Phillips SD, Wagner HR, Barth RP, Kolko DJ, Campbell Y, et al. Mental health need and access to mental health services by youths involved with child welfare: a national survey. J Am Acad Child Adolesc Psychiatry 2004;43:960-970.

18) Shin MS, Hong KE, Kim ZS, Cho SC. A standardization study of the Korean version of Learning Disability Evaluation Scale. J Korean Neuropsychiatr Assoc 1998;37:1233-1245.

19) Yoo HK, Lee J, Kang SH, Park EH, Jung J, Kim BN, et al. Standard- ization of the Comprehensive Attention Test for the Korean children and adolescents. J Korean Acad Child Adolesc Psychiatry 2009;20: 68-75.

20) DuPaul GJ. Parent and teacher ratings of ADHD symptoms: psychometric properties in a community-based sample. J Clin Child Psychol 1991;20:245-253.

21) Kim YS, So YK, Noh JS, Choi NK, Kim SJ, Koh YJ. Normative data on the Korean ADHD Rating Scales (K-ARS) for parents and teacher. J Korean Neuropsychiatr Assoc 2003;42:352-359.

22) Achenbach TM. Manual for the child behavior checklist/4-18 and 1991 profile. Burlington, VT: Dept. of Psychiatry, University of Vermont;1991.

23) Kim YH, Lee J, Moon SJ, Kim YJ, Oh KJ. Standardization study for the Korean version of the Child Behavior Checklist for ages 1.5-5. Korean J Clin Psychol 2009;28:117-136.

24) Kim MS, Lee IS, Lee CS. The validation study 1 of Korean BDI-2: in female university students sample. Korean J Clin Psychol 2007; 26:997-1014.

25) Beck AT, Steer RA, Brown GK. Beck Depression Inventory-II. San Antonio 1996;78:490-498.

26) Kovacs M. Children's Depression Inventory. 2nd edition. Pearson; 2014. Retrieved 18 February 2014.

27) Lee HG, Shin HS, Lee KS. Development of a self-report form of the Adolescent Problem Behavior Rating Scale: tests of its reliability and validity. Korean J Dev Psychol 2004;17:147-170.

28) Achenbach TM, Edelbrock CS. Manual for the youth self-report and profile. Burlington, VT: University of Vermont, Department of Psychiatry; 1987.

29) Goodman R, Ford T, Simmons H, Gatward R, Meltzer H. Using the Strengths and Difficulties Questionnaire (SDQ) to screen for child psychiatric disorders in a community sample. Br J Psychiatry 2000; 177:534-539.

30) Row KR, Suh DS. A preliminary study for developing a Child and Adolescent Functional Assessment Scale in the mental health service. J Korean Acad Child Adolesc Psychiatry 2014;25:142-155.

31) Kim JA, Ha KH, Hong HJ, Kim HY. 2013 students' mental health school-community cooperative model-management of high risk students and change in awareness of mental health in school. J Korean Acad Child Adolesc Psychiatry 2015;26:94-103.

32) Rasic D, Hajek T, Alda M, Uher R. Risk of mental illness in offspring of parents with schizophrenia, bipolar disorder, and major depressive disorder: a meta-analysis of family high-risk studies. Schizophr Bull 2014;40:28-38.

33) Dean K, Stevens H, Mortensen PB, Murray RM, Walsh E, Pedersen CB. Full spectrum of psychiatric outcomes among offspring with parental history of mental disorder. Arch Gen Psychiatry 2010;67:822-829.

34) Siegenthaler E, Munder T, Egger M. Effect of preventive interventions in mentally ill parents on the mental health of the offspring: systematic review and meta-analysis. J Am Acad Child Adolesc Psychiatry 2012;51:8-17. 